\title{
PARÁLISIS DEL TERCER PAR CRANEAL COMO ÚNICA MANIFESTACIÓN DE ARTERITIS DE LA TEMPORAL OCULTA
}

\author{
THIRD NERVE PALSY AS THE ONLY MANIFESTATION \\ OF OCCULT TEMPORAL ARTERITIS
}

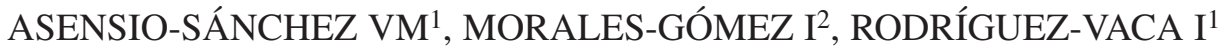

\begin{abstract}
RESUMEN
Caso clínico: Se describen dos pacientes ( 80 y 67 años) con diplopía por parálisis del tercer par craneal sin otros síntomas de afectación ocular o sistémica de arteritis de la temporal. La velocidad de sedimentación globular y la proteína C-reactiva fueron normales. La biopsia de la arteria temporal superficial confirmó el diagnóstico de arteritis de la temporal.

Discusión: Pacientes con parálisis de los nervios oculomotores podrían tener una arteritis de la temporal oculta. En los ancianos con lesiones oculares isquémicas, sin elevación de la velocidad de sedimentación, con niveles normales de proteína C-reactiva y sin síntomas sistémicos, el índice de sospecha de arteritis de la temporal debe ser alto.
\end{abstract}

Palabras clave: Parálisis del tercer par craneal, arteritis de la temporal oculta, biopsia de la temporal, diplopía, velocidad de sedimentación.

\begin{abstract}
Case report: Two patients (80 and 67 year-old) presented with diplopia for a sudden right 3 rd cranial nerve palsy without other ocular or systemic symptoms related to temporal arteritis. Erythrocyte sedimentation rate and C-reactive protein levels were normal. Subsequent biopsy of the superficial temporal artery confirmed the diagnosis of temporal arteritis.

Discussion: Patients with ocular nerve palsy could have occult temporal arteritis. Aged patients with an acute ocular ischemic lesion, without elevated erythrocyte sedimentation rate, C-reactive protein levels and systemic symptoms, should raise a high index of suspicion for temporal arteritis (Arch Soc Esp Oftalmol 2009; 84: 395-398).
\end{abstract}

Key words: Third cranial nerve palsy, occult temporal arteritis, temporal biopsy, diplopia, sedimentation rate.

\footnotetext{
Recibido: 19/2/08. Aceptado: 26/8/09.

Hospital General, Medina del Campo, Valladolid, España.

1 Doctor en Medicina.

${ }^{2}$ Licenciado en Medicina.

Correspondencia:

V. M. Asensio Sánchez

Hospital General Servicio Castellano-Leonés de Salud

Servicio de Oftalmología

Medina del Campo (Valladolid)

España

E-mail: victor_asensio@orangemail.es
} 


\section{INTRODUCCIÓN}

La arteritis de la temporal (AT) tiene una incidencia de 2,3 por 100.000 a los 60 años y del 44,7 por 100.000 a los 90 años (1). Los hallazgos oftalmológicos en AT incluyen al segmento anterior, disfunción pupilar, infartos retinianos, neuropatía óptica isquémica, oftalmoparesia, ceguera cortical, defectos del campo visual, amaurosis fugax y alucinaciones visuales complejas (2). La parálisis oculomotora es una manifestación clínica infrecuente de la AT $(1,2)$. La arteritis de la temporal oculta se define como una afectación ocular por AT sin síntomas y signos sistémicos (3). Se presentan dos casos de parálisis del tercer par craneal por AT oculta sin elevación de la velocidad de sedimentación globular con anatomía patológica patognomónica.

\section{CASOS CLÍNICOS}

\section{Caso 1}

Mujer de 80 años que acude al hospital con diplopía de 7 días de evolución. El diagnóstico fue de parálisis completa del tercer par craneal derecho con afectación pupilar. No refería cefalea, claudicación mandibular ni rigidez en el cuello y las articulaciones. Sus antecedentes personales sólo eran significativos para hipertensión arterial. Sus antecedentes oftalmológicos carecían de interés. La exploración de la motilidad ocular en el ojo izquierdo (OI) fue normal. El ojo derecho (OD) tenía ptosis palpebral y limitación de la movilidad en todas las posiciones de la mirada excepto en abduccion (fig. 1A-C). La reacción pupilar a la luz en el OI fue de $3 \mathrm{~mm}$ a $2 \mathrm{~mm}$, la respuesta pupilar en el OD fue lenta de $5 \mathrm{~mm}$ a $4 \mathrm{~mm}$ (fig. 1D). No hubo defecto pupilar aferente. La exploración con lámpara de hendidura era característica de catarata bilateral. El fondo de ojo fue normal. Una angio-resonancia magnética cerebral no detectó patología. En el estudio de laboratorio la velocidad de sedimentación globular (VSG) era de $28 \mathrm{~mm} / \mathrm{h}$, la proteína C-reactiva de $0,2 \mathrm{mg} / \mathrm{dl}$ (normal, $<0,8 \mathrm{mg} / \mathrm{dl}$ ) y las plaquetas de $175.000 / \mathrm{ml}^{3}$. El factor reumatoide, los anticuerpos antinucleares, los anticuerpos anticitoplasma del neutrófilo, anticuerpos antireceptores de la acetilcolina y la serología luética fueron negativas. El diagnóstico de AT fue considerado y se realizó una biopsia de la arteria temporal. La anatomía patológica reveló estenosis de la luz arterial con rotura de la limitante interna y células inflamatorias $\mathrm{y}$ gigantes (fig. 1E).

\section{Caso 2}

Varón de 67 años sin antecedentes personales de interés. Refiere que mientras caminaba notó de forma súbita visión doble y ptosis palpebral ligera en el OD que fue total en las horas siguientes. No tenía antecedentes oftalmológicos. No refería pérdida de peso, fiebre, claudicación mandibular o disminución de la visión. La agudeza visual en ambos ojos era de 1. La motilidad extraocular en el OI fue normal. En el OD había una ptosis total con limitación de la mirada en todas las posiciones excepto en abducción (fig. 2A-C). La motilidad pupilar era normal en ambos ojos. La presión intraocular fue de $16 \mathrm{mmHg}$ en OD y de $18 \mathrm{mmHg}$ en el OI. Los estudios biomicroscópicos anterior y posterior fueron normales. Las pruebas de laboratorio no eran significativas con VSG de $21 \mathrm{~mm} / \mathrm{h}$, proteína $\mathrm{C}$ de $0,3 \mathrm{mg} / \mathrm{dl}$ y unas plaquetas de $125.000 / \mathrm{ml}^{3}$. El diagnóstico definitivo se realizó con biopsia de la arteria temporal donde se encontró oclusión de la arteria temporal con células gigantes alrededor de la elástica interna, que aparece rota y reduplicada (fig. 2D).

\section{DISCUSIÓN}

En el primer caso descrito la historia y el examen clínico eran compatibles con una parálisis completa del tercer par craneal con afectación pupilar y en el segundo paciente sin afectación pupilar, y en ambos, sin ningún síntoma ni signo de arteritis de la temporal, la afectación oftalmológica fue la única razón de acudir a urgencias. En pacientes de 60 o más años, la sospecha de arteritis de la temporal debe ser elevada $(1,2)$. La sospecha clínica se basa en una variedad de síntomas, incluyendo cefalea, fiebre, claudicación mandibular, rigidez de nuca, pérdida de peso y astenia. Las pruebas de laboratorio, incluyendo la VSG y un estudio hematológico, pueden ser útiles $(1,2)$. La VSG alta es un criterio de diagnóstico bien establecido en AT, sin embargo, varios estudios describen pacientes con VSG entre 5 y $30 \mathrm{~mm} / \mathrm{h}$ y biopsia positiva para AT $(4,5)$. La biopsia de la arteria temporal superficial es considerada la prueba más sensible y específica 


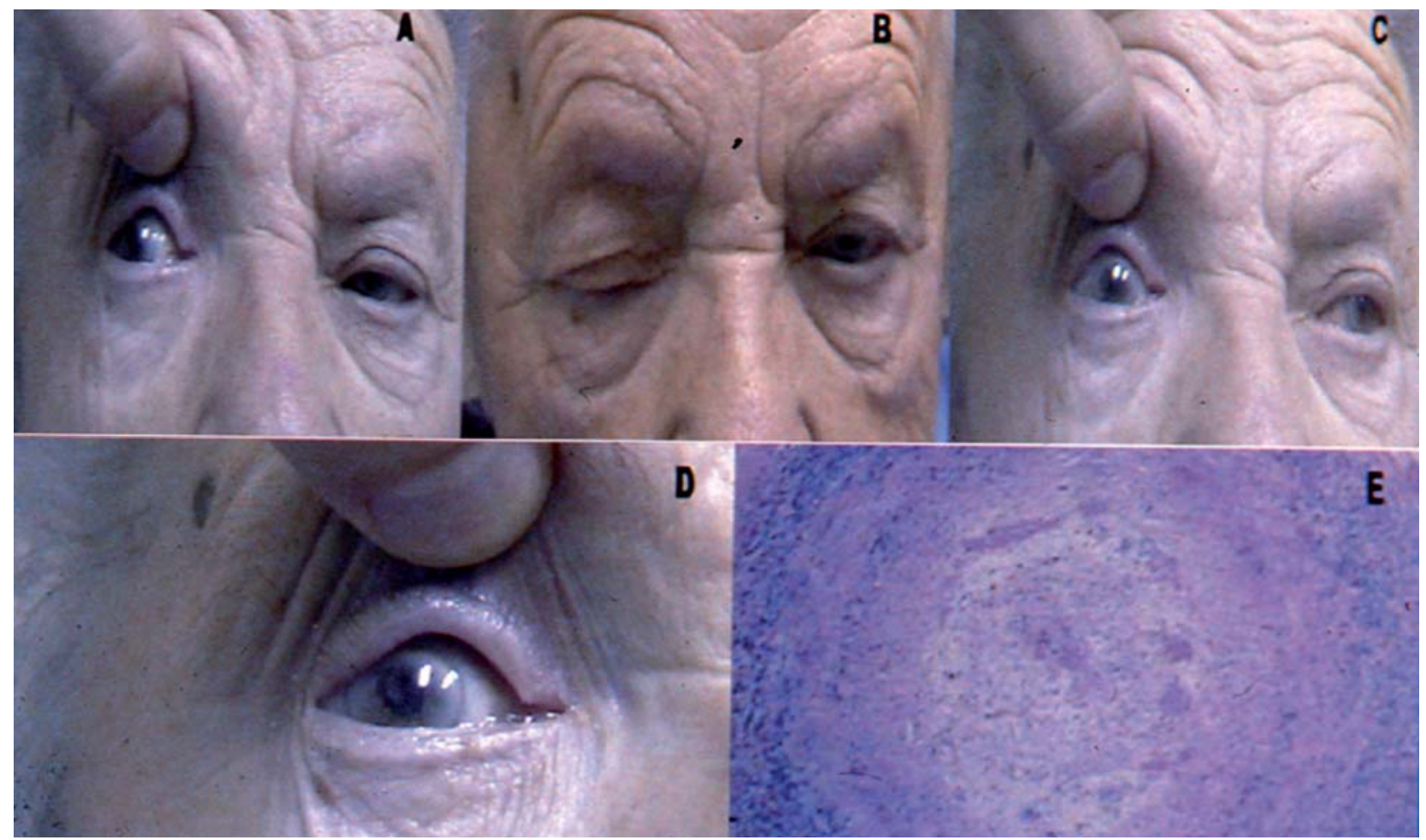

Fig. 1: Parálisis del tercer par craneal derecho. Limitación de la motilidad ocular con dilatación pupilar (A-D). Biopsia de la arteria temporal superficial izquierda (hematoxilina-eosina) mostrando oclusión de la luz arterial con células gigantes cerca de roturas en la membrana elástica interna con células inflamatorias crónicas $(E)$.

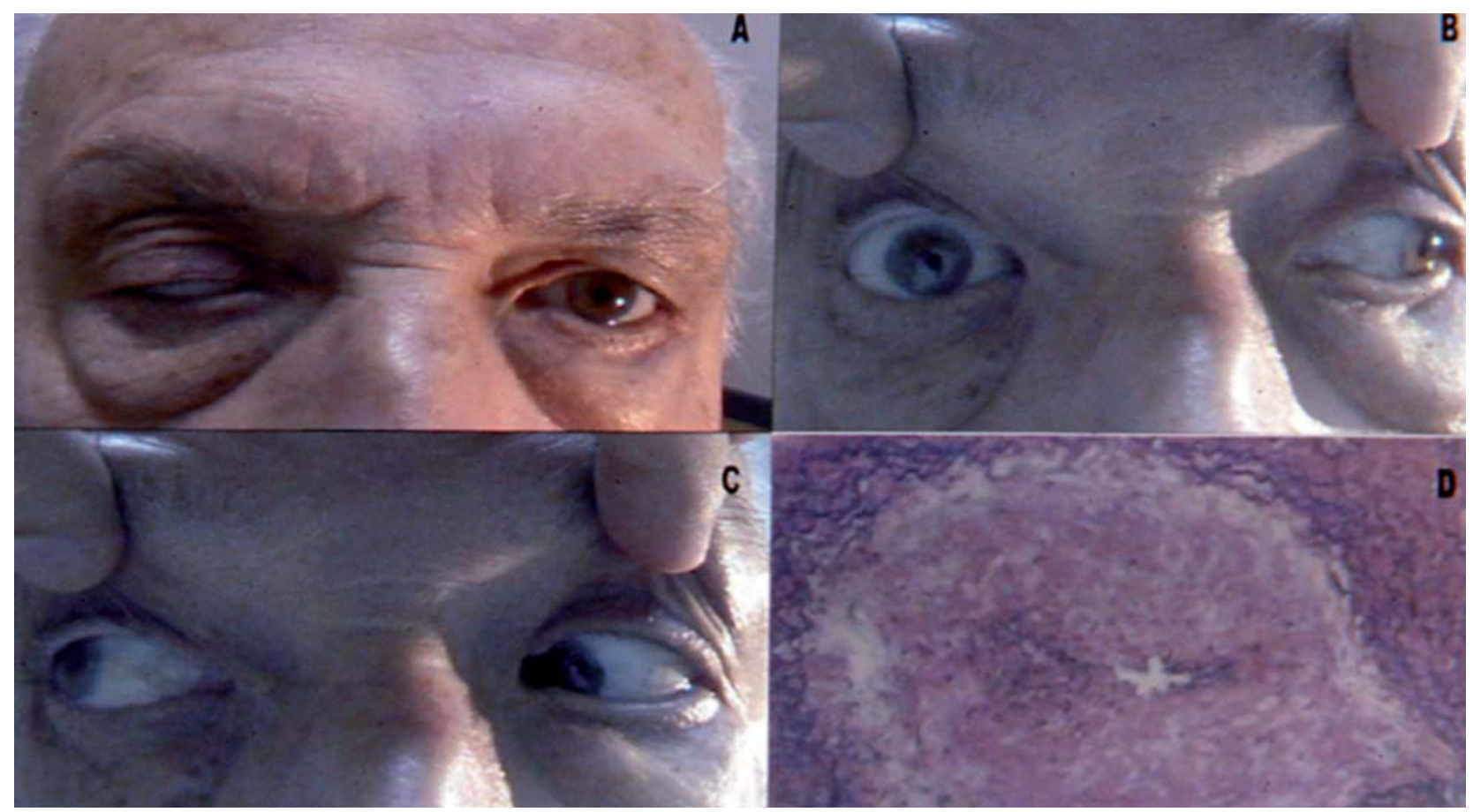

Fig. 2: Ptosis palpebral derecha con limitación de la mirada en todas las posiciones excepto en abducción (A-C). Hematoxilina-eosina de la arteria temporal con estenosis de la luz arterial y múltiples células gigantes. 
$(1,3)$. En casos sospechosos, una segunda biopsia debería ser considerada. Hayreh et al (3) describen 18 casos de AT oculta en la que los pacientes no tenían ningún signo o síntoma sistémico de AT, y los valores de la VSG y proteína $\mathrm{C}$ reactiva eran relativamente bajos. Los pacientes que presentamos acudieron a urgencias por diplopía como única clínica oftalmológica y sin signos y síntomas sistémicos que hiciera pensar una AT, lo cual podía hacer sospechar una etiología microvascular máxime cuando uno de ellos era hipertenso. El diagnóstico diferencial incluye compresión del nervio por un aneurisna, isquemia microvascular, inflamación, tumor, infiltración, infección, autoinmunidad, migraña ocular y arteritis de la temporal. La negatividad de todas las pruebas y considerar que la arteritis de la temporal es un gran simulador de otras enfermedades nos obligó a realizar la biopsia de la arteria temporal. Así, en diplopías de personas mayores debería sospecharse AT y estudiar otras posibles manifestaciones de la enfermedad. No es infrecuente encontrar en la literatura médica (neurología, reumatología, oftalmología) que el diagnóstico de AT se ha confirmado ante la negatividad del resto de las pruebas.
La VSG y la proteína C-reactiva normales pueden indicar en pacientes con una AT oculta una enfermedad más localizada y por tanto sin síntomas sistémicos (3). El diagnóstico de AT es necesario no sólo para la prevención de una enfermedad con gran morbilidad ocular, sino para prevenir las serias manifestaciones sistémicas de una enfermedad con tratamiento.

\section{BIBLIOGRAFÍA}

1. Machado EB, Michet CJ, Ballard DJ, Hunder GG, Beard $C M, C h u C P$, et al. Trends in incidence and clinical presentation of temporal arteritis in Olmsted County, Minnesota, 1950-1985. Arthritis Rheum 1988; 31: 745-749.

2. Mehler MF, Rabinowich L. The clinical neuro-ophthalmologic spectrum of temporal arteritis. Am J Med 1988; 85: 839-844.

3. Hayreh SS, Podhajsky PA, Zimmerman B. Occult giant cell arteritis: ocular manifestations. Am J Ophthalmol 1998; 125: $521-526$

4. Wise CM, Agudelo CA, Chmelewski WL, McKnight KM. Temporal arteritis with low erythrocyte sedimentation rate: a review of five cases. Arthritis Rheum 1991; 34: 1571-1574.

5. Wong RL, Korn JH. Temporal arteritis without an elevated sedimentation rate: case report and review of the literature. Am J Med 1986; 80: 959-964. 